\title{
A la sombra del Miguel Hidalgo: anÁlisis etnográfico del PARQUE CENTRAL DE TAPACHULA
}

\author{
Soledad Álvarez Velasco
}

Resumen: La exploración etnográfica del parque Miguel Hidalgo en Tapachula arroja claves para entender cómo en silencio y a la sombra en ese lugar se han configurando fronteras sociales, distinciones y prácticas teñidas de formas de violencia normalizada hacia los migrantes indocumentados en tránsito. Al localizar espacialmenteel análisis, se identifica cómo este parque, apesardeno estar marginado físicamente, es un espacio socialmente marginado. Hecho que ha permitido que en su contracara se constituya un mercado para el trabajo informal de migrantes indocumentados y un punto de operaciones para redes de trata y tráfico de personas.

Palabras clave: espacios socialmente marginados, migración indocumentada en tránsito, violencia normalizada, mercado de trabajo informal, redes de trata y tráfico de personas, fronteras sociales.

Enviado a dictamen: 25 de enero de 2010

Aprobación: 15 de abril de 2010

Revisiones: 1

Soledad Álvarez Velasco, Maestra en antropología social por la Universidad Iberoamericana de México. Temas de investigación: migración transnacional, particularmente migración en tránsito, y la relación entre violencia, migración indocumentada y Estado. Correo electrónico: gesoil@hotmail.com.
Abstract: An ethnographic exploration of the central park of Tapachula, el "Miguel Hidalgo", drops keys for understanding how, in silence and in the shadows of this urban site, social borders, distinctions and practices marked with normalized forms of violence towards undocumented migrants in transit, have been configured. By doing a localized analysis, it is possible to identify how this park, despite not being physically marginalized, is a social marginalized space. This fact has permitted that in its flipside a market for informal work of undocumented migrants and a point of operation of human trafficking and smuggling networks have been constituted.

Keywords: socially marginalized spaces; undocumented transit migration; normalized violence; market for informal work; trafficking and smuggling networks; social borders.

\section{Introducción}

$\mathrm{D}$ iariamente miles de migrantes indocumentados cruzan la frontera sur chiapaneca y de modo clandestino inician un periplo migratorio estremecedor marcado por la incertidumbre, el miedo, la espera, la violencia y, cómo no, por una incuestionable valentía. 'Son hombres y mujeres que en su mayoría provienen de países pobres, sobre todo de Centro y Sudamérica. Su afán no es precisamente quedarse en territorio mexicano, sino atravesarlo para internarse 
en el mayor polo migratorio mundial: Estados Unidos. Debido a que su ingreso legal a México está restringido —no se diga a la potencia del norte-, su tránsito sólo es posible a través del ocultamiento y del uso de vías clandestinas, que si bien no garantizan necesariamente el cumplimiento de sus objetivos migratorios, los expone permanente a inauditas formas de violencia. Continua discriminación e invisibilidad, extorsiones, robos, abusos de autoridad, estafas, golpes, accidentes, machetazos, mutilaciones, secuestros, torturas, violaciones y asesinatos, son parte de las contingencias a las que están expuestos los indocumentados que transitan por las ciudades y/o pueblos fronterizos del sur chiapaneco. Esas formas de violencia no suelen distinguir entre edad, género o nacionalidad, salvo que se trate de mujeres o de menores migrantes que viajan solos para quienes ese tránsito migratorio implica sortear peligros todavía mayores. Es más, con distinta intensidad y de diverso modo, autoridades locales, agentes migratorios; los distintos tipos de policía federal, estatal o municipal-, el ejército; miembros de la delincuencia organizada, de pandillas juveniles, de grupos de narcotraficantes; polleros o tratantes de personas; y los mismos habitantes fronterizos son parte de quienes violentan continuamente a los migrantes.

Al parecer la violencia local ha teñido las relaciones sociales que se tejen en torno a aquellos cuya única "falta" es transitar sin documentos o permisos oficiales. De hecho, en la mayoría de los casos todas esas formas de violencia no solo permanecen invisibles e impunes, sino que además quedan registradas en la memoria y en el cuerpo de los indocumentados como si ese fuese el ineluctable precio que deben pagar por cruzar México sin papeles. Es tal el nivel de violencia contra los indocumentados y la frecuencia con la que se ejerce que parecería que ésta ha terminado "normalizándose" como parte de la vida cotidiana en las ciudades y pueblos fronterizos del sur de Chiapas.

Ese "orden normal" plagado de violencias, suele estar presente sobre todo en aquellos espacios por donde cruzan y en donde eventualmente paran aunque sea por períodos de tiempo muy cortos - los indocumentados que transitan por esta parte del sur de México, particularmente por el tramo fronterizo Tecún Umán-Ciudad Hidalgo-Tapachula-Arriaga en su ruta migratoria hacia Estados Unidos. El cruce sobre el río Suchiate entre Tecún Umán —Guatemala-y Ciudad Hidalgo - México—; los albergues para migrantes; el parque central Miguel Hidalgo en Tapachula; el cruce de La Arrocera en Huixtla —entre las ciudades fronterizas de Tapachula y Arriaga-; las rutas clandestinas; o la estación y las vías férreas donde los migrantes suelen esperar al llamado "Tren de la Muerte" en Arriaga, son algunos de esos espacios por donde paran o cruzan los indocumentados. Son lugares que a pesar de no estar necesariamente marginados en términos físicos, sí están "socialmente marginados". Es más, son cruces y parajes que pese a formar parte de la vida cotidiana y de la dinámica migratoria local, parecería que en ellos el límite entre lo legal y lo ilegal, lo lícito e ilícito, ha quedado suspendido, dando paso al despliegue de distintas formas de "normal" y rutinaria violencia hacia esos hombres y mujeres sin papeles.

El objetivo de este artículo es acercarse al modus operandi de esas formas de violencia ejercidas en contra de los migrantes indocumentados. Para ello, haremos un análisis espacialmente localizado en uno de los parajes tradicionales que forma parte de una de las rutas migratorias por donde transitan los migrantes que atraviesan la frontera sur chiapaneca: el parque Miguel Hidalgo de Tapachula. Emprender un análisis etnográfico en este espacio se vuelve especialmente pertinente a la hora de hacer una exploración que nos permita - de cierto modo- interpretar críticamente el porqué de esas formas de violencia cotidiana que se gestan en torno a los indocumentados. El "Miguel Hidalgo", como se conoce localmente al parque de esta ciudad fronteriza, es un lugar al que tradicionalmente llegan, por diversos motivos, distintos tipos de migrantes indocumentados. Por tanto, al inmiscuirnos 
en la dinámica de este lugar céntrico y explorar las interacciones que ahí suceden podremos comprender, por un lado, los motivos por los que los indocumentados paran en este espacio urbano y, por otro, cómo y por qué se construyen espacios socialmente marginados donde un enjambre de ilegalidades opera en la sombra, desplegando un modus operandi sumamente violento en torno a los migrantes.

Este artículo está dividido en tres partes. En la primera sección haremos una breve referencia a ciertos apuntes teóricos que desde la geografía marxista y la antropología de la violencia arrojan ciertos elementos para analizar la configuración de espacios socialmente marginados. A lo largo de la segunda sección, y basándonos en los hallazgos etnográficos, nos inmiscuiremos entonces en el modus operandi de la cara menos visible del parque Miguel Hidalgo, aquella en la que se ha configurado un mercado para el trabajo informal de migrantes y un punto de enganche para el funcionamiento de redes de trata y tráfico de personas. Esta indagación en las relaciones sociales, plagadas de distinciones y violencias veladas, que se gestan a la sombra de este espacio urbano, nos dará pie para, en la última sección, elaborar algunas conjeturas finales y sobre todo identificar los inminentes desafíos frente a esa compleja relación entre violencias normalizadas y migración indocumentada en tránsito.

\section{Espacios socialmente marginados}

Quizá fuese más sencillo analizar lo que sucede en el Miguel Hidalgo, si ese tradicional paraje fronterizo se localizara en las barriadas marginales de Tapachula. Como afirma Loïc Wacquant (2007) las barriadas urbanas, los guetos, las favelas, las zonas periféricas, son espacios que históricamente han constituido focos de violencia donde los "condenados de las ciudades" habitan. Esos cinturones urbanos, sugiere este autor, al ser producto de una "marginalidad avanzada" propia de los Estados capitalistas, han sido el lugar destinado para pobres, migrantes, minorías étnicas, entre otro tipo de excluidos, que viven en los márgenes económicos, sociales y políticos, negados de cualquier tipo de derecho o acceso a mínimas condiciones de vida. Frente a esos barrios de relegación ni el Estado ni la sociedad suelen responder - muchas veces ni siquiera los suelen reconocer- condenando así a la violencia y a la perpetua marginación a todos esos "indeseados", al punto que las condiciones infrahumanas en las que viven son percibidas incluso como parte de un supuesto orden natural (Wacquant, 2007: 13-17, 22-25).

Si ese fuera el caso, y el Miguel Hidalgo estuviese físicamente localizado en los cinturones de pobreza de Tapachula, el trabajo analítico propuesto de algún modo se nos facilitaría. Pero ese no es el caso. El Miguel Hidalgo está en el mero centro de esa ciudad fronteriza, bastante lejos de los cinturones de pobreza urbana. No obstante, es un punto de encuentro de indocumentados, y sobre todo es un espacio donde una serie de marginaciones y violencias internas en torno a los migrantes se gestan cotidianamente. Es decir, que si bien el parque físicamente no es marginado, al parecer socialmente sí lo es. ¿Cómo y por qué sucede algo así?

La histórica producción de espacios marginados ha sido un hecho indisociable de la acumulación capitalista. En ese "proceso de desarrollo geográfico desigual" (Harvey, 2003) los espacios marginados no deben ser comprendidos como meros contendores aislados de procesos sociales, sino como producto de la práctica humana y de un modo específico de organización social desigual (Harvey, 2007 [1977]). Este planteamiento es clave ya que pone en tela de duda a una matriz de pensamiento que tendería a naturalizar la marginalidad global, analizándola únicamente como si fuese un hecho físico "dado" que responde a un "orden natural" determinado. Es primordial cuestionar y refutar esos a priori, y sobre todo resaltar el rol de las prácticas humanas en la construcción social del espacio, 
quebrando esa noción "natural" y supuestamente insalvable de las distancias espaciales y sociales existentes. El espacio es ante todo una construcción social que responde a procesos históricos y políticos determinados y a formas específicas de organización social (Harvey, 2004 [1990]; Bourdieu, 1999).

Ahora bien, en el medio de esa "geografía de la desigualdad", como acertadamente la nombra David Harvey a la actual época contemporánea, difícilmente existirá un espacio libre de distancias sociales que se generan como parte de relaciones de poder desiguales. Así, las jerarquías y distancias sociales, inherentes a una sociedad de clases y de distinciones, no solo están presentes en diversos espacios sino que casi siempre suelen estar "enmascaradas por ese efecto de naturalización", o de normalización de una rutina de exclusión y dominación (Bourdieu, 1999). Al adentrarnos en el modus operandi de un espacio determinado, que quizá físicamente no esté marginado, como es el caso del parque Miguel Hidalgo, es posible entonces identificar jerarquías, marginaciones, conflictos de clase, distinciones e incluso, de manera muy sutil, diversos tipos de fronteras intangibles — sociales, culturales, políticas, lingüísticas, étnicas y también corporales - que se configuran en la práctica social (Harvey, 2007 [1977]; Bourdieu, 1999; Mummert, 1999). Al interior de esas formas sociales se establecen ciertos códigos que si bien pueden ser imperceptibles a primera vista, otorgan privilegios a unos y posibilitan el dominio y la exclusión de otros, generalmente de todos aquellos que "naturalmente" han pertenecido a las periferias e históricamente han sido marginados y desplazados. Es más, sólo a partir de la introspección en formas espaciales concretas y en su modo de funcionamiento, como en el parque central de Tapachula, es posible identificar y analizar las diversas maneras en las que se ejerce y se afirma el poder y como efecto - a veces de manera inadvertida y en muchos casos de forma más evidente- los modos en que diversas formas de violencia tiñen las prácticas cotidianas.
En este punto cabe señalar que la violencia ha de ser comprendida también como producto de relaciones de poder asimétricas que están determinadas por el contexto histórico y político local y global —es decir, es producto directo de ese desarrollo geográfico desigual- y que lejos de ser un fenómeno social fijo y de un solo tipo, la violencia es diversa y cambiante (Sheper-Hughes y Bourgois, 2004). De hecho, la penetración en las interrelaciones sociales que se gestan en espacios física y/o socialmente marginados es una poderosa vía para acercarnos a un análisis que dé cuenta de la complejidad y multidimensionalidad que tiene la violencia y de los mecanismos que se usan para efectivamente invisibilizarla. ${ }^{2}$

Por tanto, para desenmascarar esas sutiles formas de violencia normalizada, en sus diversas dimensiones, hemos de "localizar espacialmente" nuestro análisis para así desnaturalizar las violencias que se han colado en las interrelaciones sociales. ${ }^{3}$ Al localizar estaríamos necesariamente adentrándonos en los confines de contextos nacionales específicos, donde se pondría en evidencia cómo esa geografía de la desigualdad es producto de procesos sociales y políticos que acontecen en el seno de un Estado determinado (Harvey, 2004 [1990]; Bourdieu, 1999; Wacquant, 2007; Sassen, 2003; Das y Poole, 2004).

Así, sólo un análisis localizado nos dará la pauta para vislumbrar cómo espacios sociales que, como el Miguel Hidalgo, estratégicamente han sido marginados, son el resultado de relaciones que adoptan formas espaciales y sociales específicas y que se vuelven inteligibles cuando se las analiza a partir de una localización espacial e histórica particular en relación con el contexto capitalista global. Y, además, cómo esa violencia normalizada, que opera en la sombra de este parque central, no responde a un orden "natural", sino que es producto de formas particulares en las que el Estado mexicano, y particularmente la sociedad tapachulteca, se han relacionado con los indocumentados. 


\section{La contra cara del parque Miguel Hidalgo}

El Miguel Hidalgo es uno de los espacios urbanos más concurridos y más dinámicos comercial, financiera, política y culturalmente en Tapachula. En uno de sus extremos se ubica la sede del Ayuntamiento Municipal, y en el otro una zona de restaurantes. Alrededor del parque se hallan algunas edificaciones históricas y centros culturales, como la iglesia de San Agustín o el antiguo Palacio Municipal, donde actualmente funciona la Casa de la Cultura y el Museo Arqueológico del Soconusco (Secretaría de Turismo del Gobierno de Chiapas, 2004; Ayuntamiento del Municipal de Tapachula, 2008). Asimismo, en las calles aledañas se encuentran una serie de almacenes, bancos, pequeños negocios y algunas oficinas de gobierno. En este lugar céntrico suelen estar presentes boleros y globeros, diversos tipos de vendedores ambulantes, y por supuesto la policía municipal, que ronda el parque y se cruza con las decenas de transeúntes y visitantes cotidianos. Pocos supondrían que un enjambre de ilegalidades y violencias se teje por detrás de esa "normal" apariencia citadina.

Si por algún motivo este parque también se ha convertido en un símbolo de Tapachula es por ser un espacio al que confluyen, por varias causas, los migrantes que llegan hasta esta ciudad fronteriza. Algo que a pesar de no ser del todo evidente ocurre diariamente. De hecho, una de las recomendaciones que varios informantes locales hacen a cualquier investigador(a) interesado en analizar la complejidad migratoria local es ir hasta el parque central, especialmente un día domingo, y explorar lo que ahí acontece. ${ }^{4}$ Para comprender la dinámica del Miguel Hidalgo es necesario tener en cuenta que Tapachula es una de las ciudades fronterizas más importantes del sur de Chiapas. Hasta el año 2005 esta urbe era uno de los lugares más concurridos dentro de la ruta migratoria de sur a norte, ya que se constituía como punto de salida del tren costero de carga Chiapas Mayab. Hecho que convertía a Tapachula en una parada obligada de miles de indocumentados que usaban el tren como medio de transporte en su tránsito al norte. Si bien el paso del huracán Stan destruyó las vías férreas, con lo cual disminuyó la afluencia de migrantes, Tapachula no ha dejado de ser un punto clave en la ruta migratoria ni en la dinámica de la frontera sur chiapaneca, especialmente dentro de la región fronteriza del Soconusco. ${ }^{5}$

Al ser Tapachula capital regional y el segundo polo económico de Chiapas, cuenta con una importante infraestructura comunicacional terrestre, marítima, fluvial y aérea que la vuelve atractiva para gestionar tránsitos migratorios globales, oficiales y clandestinos. Se calcula que $57.8 \%$ del total de ingresos de indocumentados a México ocurre, actualmente, a través de la frontera sur chiapaneca, especialmente a través del Socunusco (Gobierno del Estado de Chiapas, 2009). De hecho, datos del Instituto Nacional de Migración, INM, dan cuenta de que entre 2005 y 2008 solo desde la Delegación Regional Chiapas en Tapachula se habrían detenido y deportado anualmente alrededor de 50.000 indocumentados (INM, 2009). Sin embargo, y de acuerdo con los propios agentes migratorios de esta entidad, el número de migrantes que consiguen ingresar al país sin ser detenidos corresponde, aproximadamente, al doble de los que son efectivamente detenidos y deportados. Así, se estima que entre 2005 y 2008 alrededor de 100.000 migrantes habrían atravesado cada año esta frontera de manera clandestina. ${ }^{6}$ Debido a la cercanía geográfica y a un proceso migratorio históricamente sostenido, la gran mayoría de migrantes detenidos en Tapachula son centroamericanos, principalmente de Guatemala, Honduras, El Salvador y Nicaragua. No obstante, los datos oficiales de detenciones realizadas desde esa ciudad durante 2007 dan cuenta de que, sólo en ese año, también se detuvieron a migrantes provenientes de 50 países diferentes de África, Asia, Europa y América (INM, 2007). Datos que remarcan la importancia que tiene Tapachula dentro del circuito migratorio local y global. 
El parque Miguel Hidalgo cumple un rol clave a la hora de analizar ciertos aspectos de la migración local, sobre todo aquello que se silencia y se oculta estratégicamente. Por un lado, este espacio se ha convertido en una suerte de mercado para el empleo informal donde los migrantes indocumentados trabajan, ya sea como boleros, globeros o vendedores ambulantes, muchas veces esclavizados a redes de explotación laboral. También es un paraje donde los sin papeles suelen ser contratados por empleadores tapachultecos que llegan hasta sus inmediaciones para contratar mano de obra barata para ciertas "chambas" temporales. Pocas veces los migrantes logran negociar sus condiciones laborales. En la mayoría de los casos no les queda otra alternativa que aceptar aquello que los tapachultecos ofrezcan, sin importar que casi siempre existan abusos y violaciones a sus derechos laborales. Directamente ligado al empleo informal y a la necesidad que la gran mayoría de migrantes indocumentados tiene de encontrar un trabajo y juntar dinero ya sea para continuar la ruta al norte o para enviar remesas a sus familias, el parque igualmente se ha convertido en un lugar estratégico donde tratantes y traficantes de personas tranzan y enganchan a víctimas, sobre todo a mujeres indocumentadas, ofertándoles diversos tipos de trabajo. Por otro lado, ese mismo espacio céntrico también se ha transformado en un lugar propicio para la socialización de los migrantes. Este es uno de sus lugares de encuentro y de diversión semanal, y para aquellos migrantes que están en tránsito, el parque incluso puede ser un sitio de encuentro con nuevos compañeros de ruta, de espera e incluso pernocta antes de continuar su tránsito migratorio. Además, al ser uno de los espacios nodales de la vida de Tapachula, en el parque es posible explorar las formas en que los habitantes de la ciudad, así como las autoridades locales, interaccionan o no con los indocumentados; a la vez se pueden identificar una serie de fronteras y distancias sociales que dan cuenta de sutiles formas de violencia hacia los migrantes y de una gran tolerancia estratégica frente a todo lo que allí ocurre. Como vemos esa "normal" apariencia citadina del Miguel Hidalgo esconde una realidad bastante más compleja que al parecer opera a la vista de todos pero que muy pocos la ven.

Esos aspectos ocultos del parque central — ser un mercado para el trabajo informal, un punto de enganche y tranza de redes de tráfico y trata de personas, un lugar de encuentro y de socialización para migrantes indocumentados y un espacio constituido por fronteras y distancias sociales internas - no son en lo absoluto fáciles de identificar y menos aún de analizar. De hecho, esa contracara del parque central, al tejerse en torno a la migración indocumentada, tiende a ser, al igual que esta última, estratégicamente invisibilizada, y esto se debe a una razón: la ubicación física del parque Miguel Hidalgo. Al estar inserto en pleno centro de la ciudad, al pie del Ayuntamiento Municipal y muy cerca de otras entidades públicas locales, ese entramado de ilegalidades junto con su modus operandi y las diversas formas de violencia que genera hacia los indocumentados, quedan ocultos. De hecho, la dinámica del parque, en contraste con lo que puede ocurrir en el albergue, en las vías férreas o en otros cruces de ese tramo fronterizo, no gira exclusivamente en torno a los flujos migratorios. En este paraje existe una intensa actividad económica, social, política y cultural propia a la que se suman - y en la que entonces quedan mimetizados- los migrantes indocumentados así como ese entramado social que se teje en torno a ellos. Es más, identificar en el parque a migrantes sin papeles, que suelen estar escondidos y confundidos entre los tapachultecos, acercarse y dialogar con ellos, es todo un desafío; no se diga descifrar códigos y fronteras sociales excluyentes, localizar a empleadores, polleros o tratantes de personas y entender el modo que tienen de operar. Así, la cara visible del parque, su dinámica cotidiana y su centralidad, opacaría a su contracara que es precisamente la que interesa explorar. 
Esta invisibilización, a no dudarlo, supone claros desafíos metodológicos, ya que estaríamos tratando de interpretar las interacciones de un entramado social "fantasma" - invisible, pero presente- difícil de identificar y de analizar en sus prácticas cotidianas. Esa limitante se vincula con algo más. Si bien a primera vista la centralidad del parque podría suponer una ventaja analítica, no lo es. Como ya mencionamos, su ubicación física se convierte en una de las causas para que esa realidad paralela esté así de oculta. Esa ambivalencia nos exige preguntarnos por el nexo existente entre centralidad física y producción de marginalidades sociales, también por la relación que hay entre la autoridad local, su permisividad -o estratégica permisividad-y el funcionamiento de esas redes de ilegalismos. Sólo por citar un ejemplo, el Ayuntamiento Municipal y todo su aparato burocrático estarían, sospechosamente, en primera fila "observando" esa realidad invisible que ocurre en las inmediaciones del parque. De este modo, tendríamos dos claras limitaciones analíticas: un espacio social ambivalente y un entramado social "fantasma".

A pesar de esas limitaciones, hay un hecho que permite iniciar un proceso de desenmascaramiento de esa realidad oculta: la dinámica dominguera en el parque central. El domingo de cada semana, la "normal" rutina del parque se suspende y de algún modo queda en evidencia la interacción diaria que los migrantes indocumentados tienen en la vida cotidiana tapachulteca, así como el accionar de un enjambre de ilegalidades que se teje a su alrededor. De este modo, y tomando en cuenta esas limitaciones, en la etnografía realizada hemos conjugado diversos métodos de estudio para explorar esos aspectos presentes en la contracara de este espacio social. Toda la información recaba nos ha permitido reconstruir — de alguna manera- el modus operandi de ese entramado social "fantasma". Indaguemos entonces esos aspectos del parque Miguel Hidalgo que estratégicamente han sido invisibilizados y puestos a la sombra.

\section{Mercado para lo informal}

Al interrogar a diversos informantes locales sobre la relación existente entre el parque, la migración indocumentada y el trabajo informal, muchos solían hacer una rápida y clara distinción entre algunos tipos de migrantes que llegan hasta el parque. Así, diferenciaban entre las "domésticas", los "canguritos", y los "otros migrantes". Detengámonos en el interesante testimonio de Amalia, una tapachulteca de 26 años que trabaja desde hace 4 años como dependiente de uno de los principales almacenes de ropa de mujer ubicados en una de las calles aledañas al parque central. Su percepción de algún modo sintetiza lo que varios otros informantes locales piensan del parque y de los migrantes que hasta ahí llegan:

[...] Claro que llegan migrantes y no sólo al parque también vienen a comprar. En el parque siempre están los jovencitos que venden caramelos. A ellos les dicen "canguritos" y son de Centroamérica [...] Estos jovencitos van por el centro de la ciudad vendiendo y llegan al parque. Tendrán 18 años como máximo. A mí me da la impresión de que han de ganar bien poquito. Todos los días se los ve por el parque y caminando por las calles, icon el sol y el calor de Tapachula! La tienen bien dura los pobres muchachitos [...] También están las muchachas de Guatemala, que son "domésticas" [empleadas domésticas] en casas de gente adinerada de aquí de Tapachula. Ellas no vienen todos los días al parque. El día que más llegan es el domingo porque tienen libre. En cambio, a los comercios de aquí cerca sí vienen otros días. Lo que pasa es que ya no se visten con esos trajes típicos que se ponían como antes. Cada vez vienen más vestidas como nosotras o combinadas: que si se ponen una falda de mezclilla y sus blusas de colores bordadas, que si están con sus faldas típicas y sandalias de tacón, que si usan playeras. Se compran ropa, eso les gusta [...] Los otros migrantes, los que están de paso se van al Belén [albergue El Belén] o 
se siguen derecho hasta agarrar el tren. No vienen al parque porque si no el parque fuera peligroso y no es. La verdad es que las muchachas de Guatemala y los canguritos son tranquilos y están ahí haciendo lo suyo, no hacen mucho ruido (Amalia. Tapachulteca y dependiente del almacén ubicado alrededor del parque central. Tapachula, julio 2008).

Parecería que entre los indocumentados existiesen ciertas "distinciones" ligadas al rol social que cumplen en la vida cotidiana de Tapachula. ${ }^{8}$ Los unos, "domésticas" y "canguritos", son claramente identificados por Amalia. Son nombrados y mínimamente se reconoce quiénes son, de dónde vienen, qué hacen - tanto en el parque como en la ciudad-, cuál es su rutina semanal y la importancia del domingo dentro de la misma, e incluso, en el caso de las "domésticas", cómo ciertos hábitos - por ejemplo, la vestimenta y el consumo - se han ido modificado a partir de su llegada a Tapachula. Canguritos y domésticas al ocupar nichos laborales particulares quedarían de algún modo "distinguidos" entre los migrantes indocumentados. Si bien el lugar social que ocupan sigue siendo un espacio de exclusión, ser empleada doméstica y vendedor ambulante indocumentados no asegura ninguna ventaja social y menos aún garantiza el acceso a derechos básicos, por lo menos les permite ser, en algún modo, diferenciados. En cambio, los "otros migrantes", como los designa Amalia, que son en la mayoría de los casos migrantes indocumentados que pueden estar en tránsito, se agregan bajo una misma categoría. Son prácticamente invisibles, muy poco se sabe de ellos, qué hacen en el parque, por qué han llegado o qué harán después. Se los vincula con el peligro y con lo que ocurre a la sombra del Miguel Hidalgo. ¿Por qué sucedería algo así?

\section{Las "domésticas"}

Si bien no se sabe con certeza desde cuando las domésticas vienen migrando e insertándose en la vida laboral tapachulteca, a partir de testimonios recabados y de la revisión bibliográfica hecha, se pueden inferir algunos argumentos. ${ }^{9}$ Este tipo de migración estaría posiblemente relacionado con el flujo migratorio de centroamericanos, específicamente de guatemaltecos, que desde finales del siglo XIX han llegado hasta el Soconusco. Una primera experiencia en algo así como el servicio doméstico podrían haberla tenido las esposas, hijas o parientes mujeres de jornaleros guatemaltecos que acompañaban a sus padres o familiares durante el ciclo de la cosecha del café (Arriola, 1995; De León Orozco; Casillo, Toussaint Ribot y Vásquez Olivera, 2006). ${ }^{10}$ Esa tendencia se ha mantenido desde entonces, pero ha ido tomando rasgos particulares en el transcurso del siglo XX e inicios del XXI debido a las tendencias migratorias globales, entre ellas la feminización de la migración, así como a procesos sociales y políticos acontecidos en los países centroamericanos (Castles y Miller, 2004; Rojas Weisner, 2007; Centro de Derechos Humanos Fray Matías [CDHFM] y Ecosur, 2004)."

A esta explicación de corte histórico, se sumaría que a lo largo de la década de 1990 el incremento de la emigración de chiapanecos a Estados Unidos y Canadá habría dejado nichos laborales vacíos que fueron llenados por migrantes centroamericanos, en su mayoría indocumentados. Un claro ejemplo es el trabajo doméstico (Villafuerte Solís, 2008; CDHFM y Ecosur, 2004). Así, debido a esa necesidad de mano de obra barata y a la cercanía geográfica, desde hace más de dos décadas se habrían ido configurando redes sociales compuestas por familiares, parientes y amigos(as) que "jalan" permanentemente hasta Tapachula a migrantes centroamericanas, en la mayoría de los casos indígenas guatemaltecas, muchas de ellas menores de edad, que trabajan como domésticas sin ningún documento migratorio o contrato laboral. ${ }^{12}$ Debido sobre todo a la cercanía geográfica, las migrantes guatemaltecas permanecen en Tapachula trabajando por unos cuantos meses. ${ }^{13}$ Regresan a sus localidades de origen y después de una temporada retornan a México. En otros casos, 
se trata más bien de migrantes indocumentadas en tránsito provenientes, en menor medida, de Honduras, El Salvador y en contados casos de Nicaragua, que se emplean como domésticas hasta juntar el dinero necesario y continuar con la ruta migratoria al norte (Casillas, 2006; Rojas Weisner, Fernández Casanueva y Ángeles, 2008; CDHFM y Ecosur, 2004).

Así, esa "distinción" hacia las domésticas dataría posiblemente desde hace más de un siglo, y desde hace dos décadas se habría configurado un nicho laboral específico junto con redes sociales en torno a esas migrantes indocumentadas. Podríamos entonces sugerir que los habitantes de esta ciudad, como Amalia, están históricamente habituados a la presencia cotidiana de mujeres migrantes indocumentadas, sobre todo de indígenas guatemaltecas, trabajadoras domésticas; y en aquellos estratos sociales donde se emplea esta mano de obra barata además dependen de este tipo de migración. Es casi como si se hubiese generado una suerte de familiaridad histórica - $-\mathrm{y}$ de necesidad económica y social también - hacia un "otro" excluido donde lo que menos interesa es su condición migratoria, si su estancia es temporal o si se trata más bien de una migrante en tránsito.

Directamente ligado a esa familiaridad histórica, el parque central se habría convertido en el escenario habitual designado para que empleadores(as) encuentren mano de obra barata, y para que ese "otro" familiar - las domésticas - tenga, por lo menos una vez a la semana, un momento de recreación, mientras se lleva a cabo el proceso de contratación. A pesar de que tampoco se sabe con exactitud desde cuando el parque central se convirtió en el lugar para contratar a las domésticas — de hecho la mayoría de informantes locales entrevistados frente a esa pregunta simplemente responde, "siempre ha sido así"-, en ese espacio una serie de prácticas locales, entre ilegales y violentas, se han establecido como parte de la "normal" relación con las domésticas. El domingo es sobre todo el día cuando se contratan a migrantes indocumentadas para emplearlas en el servicio doméstico. A la vista de todos, una rutina de contratación se gesta, en la cual muy poco interesa si estas mujeres tienen o no papeles migratorios en regla, sean menores de edad, que esté prohibido en la Ley Federal del Trabajo contratar a indocumentados(as) o que se esté fomentado el trabajo infantil. Las domésticas en la mayoría de los casos simplemente acatan las ofertas laborales como si fuesen órdenes, tienen muy poca capacidad de negociación y los empleadores(as) son quienes, muchas veces, unilateralmente imponen las reglas. Esto que "siempre ha sido así", que nunca ha sido regulado y que opera verbalmente sin ningún contrato escrito de por medio, ha dado pie para que una serie de violencias hacia las domésticas, o "envueltitas" como también se las llama despectivamente, haciendo alusión a su traje típico, sea parte de la rutina del trabajo doméstico. Estas trabajadoras reciben los sueldos más bajos de la región. Generalmente ganan entre 500 o 1.000 pesos por jornadas laborales que casi siempre superan las ocho horas diarias, aun cuando la Ley Federal del Trabajo establezca que el salario mínimo es de 1,485 pesos por un máximo de ocho horas laborales al día (DPLF et al., 2008). En la mayoría de los casos las domésticas no cuentan con ningún tipo de seguro social, y al estar "amparadas" bajo un contrato verbal pueden ser despididas intempestivamente o se les puede retener injustificadamente su salario. En la rutina de contratación casi nunca se estipula la firma de un contrato, documento requerido por INM para tramitar una Forma Migratoria de un Trabajador Fronterizo, FMTF, que de algún modo resguardaría el cumplimiento de ciertos derechos al otorgarles por lo menos documentos para una legal estancia. Además, muchas veces estas mujeres son víctimas de amenazas, maltratos verbales o físicos, continuos abusos y acoso y/o violaciones sexuales en los ámbitos laborales e incluso pueden ser "vendidas" por sus empleadores a redes de tráfico o trata de personas (DPLF et al., 2008; Casillas, 2006). Es decir, que no solo se ha "pasado la voz" y se ha vuelto una "costumbre" contratar a 
indocumentadas en el parque, sino también violentar de diversas maneras a esas "otras" familiares. ${ }^{14}$

Posiblemente esa histórica relación de dominación hacia las domésticas también pueda explicar de alguna manera por qué entre estas migrantes indocumentadas existe una suerte de "aceptación" a esas formas de violencia así como una actitud de servilismo y de miedo ante sus empleadores(as). Esta percepción se ha transmitido de generación en generación logrando que las "domésticas" asuman como "normales" esos maltratos e incluso que sin importar la violencia y debido a las limitadas condiciones socioeconómicas en sus países de origen, insistan en incorporarse a ese nicho laboral (Casillas, 2006; CDHFM y Ecosur, 2004).

Esta particular forma de relacionarse con las migrantes ocurre a la vista de todos y con la recurrente inacción de las autoridades locales que no regulan, no controlan, y por ende muy poco hacen por impedir este tipo de contratación ilegal y todas las formas de violencia que de esta práctica cotidiana pueden derivar. Y quién sabe, si acaso las mismas autoridades locales no resulten también beneficiadas de esa mano de obra barata e indocumentada trabajando en sus propias casas.

La presencia histórica y continua de las domésticas y esa particular dinámica de contratación e interacción plagada de sutiles formas de violencia entre los tapachultecos y ellas está complemente arraigada en la vida cotidiana no solo del Miguel Hidalgo, sino de esta ciudad fronteriza. Al inmiscuirnos en la producción de esa "distinción", de algún modo estaríamos develando la punta del iceberg de las violencias ocultas que se tejen en la contracara del parque central. La histórica tolerancia a los ilegalismos que giran en torno de estas migrantes indocumentadas habría determinado, de cierta manera, que el parque se convierta en un espacio donde se toleren diversas formas de ilegalismos. A la sombra aquello que ocurre con las domésticas y su proceso de contratación - históricamente repetidose habría normalizado y de modo consuetudinario incluso se habría convertido en un código social de relacionamiento hacia los indocumentados, canguritos y otros migrantes. Esto posiblemente habría dado paso para que el parque tenga una suerte de marca social implícita, no dicha pero presente, como el espacio central -incluso físicamente - donde paran los migrantes indocumentados $y$, a la vez, donde se da paso a una serie de prácticas ilegales y violentas que configuran un mercado para el trabajo informal.

\section{"Canguritos" en el parque central}

Al igual que las domésticas, esa "distinción" hacia los canguritos, producto del rol social que cumplen, es estratégica y sumamente ambivalente. Si bien diariamente se los ve en el parque central, se los distingue por las calles aledañas del mismo, se interactúa con ellos, aunque sea por cuestión de segundos en una rápida transacción de compra y venta, e incluso se los nombra; poco parecería importar su condición migratoria y menos aún los entramados de ilegalismos y las diversas formas de violencia que se han tejido a su alrededor. Todo eso ha quedado complemente invisibilizado al punto que parecería "normal", además de contratar a domésticas, que niños o adolescentes indocumentados vivan y sean explotados diariamente en el Miguel Hidalgo.

Estos pequeños migrantes, los canguritos, además de trabajar en el parque central cargan un estigma que los animaliza con total normalidad sin que nadie se percate que desde la forma en la que son nombrados - como animales - se construye una clara exclusión y una negación de cualquier derecho. Son "canguros" o "burros", no niños o adolescentes migrantes. ${ }^{15}$ Ellos trabajan sin descanso más de 12 horas diarias, de lunes a lunes. Algunos paran a medio día para comer algo y otros siguen de corrido en una jornada única mientras rondan el parque y sus calles aledañas. Al finalizar el día, algunos regresan a los cuartos donde generalmente duermen hacinados con varios menores migrantes que 
también se emplean en diversos trabajos informales callejeros. Otros, simplemente se acomodan entre los bancos del parque o entre los dinteles de las puertas de los negocios cercanos. Tener dónde dormir o qué comer casi siempre depende de los "jefes" para los trabajan, recibiendo, en promedio, un salario de 50 pesos diarios. Y así transcurre su día con día: entre el sol, los caramelos, el parque, la rutinaria explotación laboral y el anhelo de juntar un poco de dinero para ayudar a sus familias en sus países de origen y/o para continuar con su tránsito hasta Estados Unidos. Casualmente, el mismo anhelo que cualquier otro migrante indocumentado adulto en Tapachula podría tener.

Los canguritos son niños y adolescentes que en su mayoría tienen entre 10 y 18 años. Como las domésticas, la mayoría provine de Guatemala, aunque cada vez hay más canguritos oriundos de El Salvador, Honduras e incluso unos cuantos llegan desde Nicaragua (Casillas, 2006). ${ }^{16} \mathrm{Si}$ algo tienen en común estos niños migrantes además de compartir su condición de ser indocumentados es que su presencia en el parque se explica por su vinculación con redes de explotación laboral. De hecho tanto investigaciones realizadas por organizaciones nacionales e internacionales que trabajan en torno a los derechos de los migrantes, así como varios testimonios recabados en Tapachula, concuerdan en que por detrás de cada uno de esos canguritos, una compleja red de explotación laboral -que en poco se diferencia con formas de esclavitud infantil— se habría montado. ${ }^{17}$

En algunos casos esos pequeños vendedores que deambulan a veces solos, otras veces en pares o en tríos, son "migrantes fronterizos" que diariamente cruzan el río Suchiate y llegan al parque para trabajar y así aportar en la economía familiar. Generalmente migran, de manera clandestina, de la mano de familiares, amigos o parientes que los jalan y los "emplean" como vendedores ambulantes en el Miguel Hidalgo. Si bien a simple vista parecería que esos niños y adolescentes trabajan solos, muchas veces sus mismos padres, madres, tíos o vecinos, pueden estar sentados en una banca o en una esquina del parque, y sin que nadie sepa vigilan su trabajo diario. En otros casos, se trata más bien de "migrantes indocumentados en tránsito" que paran en Tapachula para reunir dinero y continuar su ruta hacia Estados Unidos. Increíblemente muchas veces estos menores - usando las mismas rutas y estrategias que un adulto migrante, por ejemplo que una doméstica - emprenden periplos migratorios con el objetivo de (re)encontrarse con sus padres y/o madres migrantes, y a la par escapar de la soledad propia de la reconfiguración familiar producida por la migración, la inseguridad y la violencia cotidiana en sus países de origen. Estos pequeños suelen iniciar solos ese tránsito y es muy común que en el camino se encuentren con otros niños o adolescentes en su misma condición. Así, llegan en pares o en tríos hasta Tapachula y en el parque son "contratados", más bien dicho "atrapados", por redes de explotación laboral. O muy fácilmente puede ser que en el medio de su tránsito migratorio terminen enredados con traficantes o tratantes de personas, que se aprovechan de su soledad y fragilidad. Usualmente los traficantes insertan a esos niños y adolescentes - casi que de forma esclavizada - en el mercado informal del Miguel Hidalgo "empleándolos" en varios trabajos: como canguritos por las mañanas, y/o en redes de prostitución infantil por las noches. Incluso existen casos de menores que en el medio de su tránsito migratorio y al ser abandonados en alguna localidad fronteriza o en Tapachula por redes de polleros, que sus padres y/o madres migrantes en Estados Unidos contrataron para emprender un proceso de reunificación familiar clandestina, son fácil presa para que esas mismas redes de explotación laboral los "empleen" como canguritos y también los inserten en el nefasto mundo oculto de la trata, explotación sexual o comercio de menores. ${ }^{18}$

Como vemos, por detrás de esa cotidiana figura del parque central se esconden diversos motivos 
para migrar, distintas estrategias migratorias y varias redes - de familiares, y de traficantes y tratantes de personas - que de diversas maneras jalan y atrapan a esos menores indocumentados. Los canguritos, además de ser quienes surten con dulces y cigarrillos a los transeúntes tapachultecos, son, de diversas maneras y con distinta intensidad, víctimas de inauditas formas de violencia que pasan completamente desapercibidas en este espacio urbano y que desde por lo menos hace dos décadas han venido normalizándose como parte de una práctica cotidiana de relacionarse hacia ese tipo de migrantes.

¿Cómo es posible que este enjambre oculto se geste día con día detrás de los canguritos? Sus propios testimonios, así como de funcionarios públicos y privados, algunos reportajes de la prensa local e incluso ciertas recomendaciones hechas por la Comisión Nacional de Derechos Humanos, CNDH, en Tapachula, revelan que la presencia oculta de esas redes en el parque central solo podría explicarse debido a una tolerancia estratégica y, sobre todo, a la inserción beneficiosa de ciertas autoridades locales en esos enjambres de ilegalidades. ${ }^{19}$ Es decir, la clara inacción tanto del gobierno local, estatal y federal - específicamente de INM - y su poco control en la frontera sur chiapaneca y en ciertos parajes como el parque central permitirían la existencia y multiplicación de esas redes. Inacción que no es casual, todo lo contrario, tiene una causa: recibir ciertos beneficios a cambio de la presencia de los canguritos en el parque. Así, unos reciben réditos económicos directamente de los traficantes y tratantes de personas, y otros extorsionan a esos menores migrantes para permitirles su estancia y trabajo diario en el Miguel Hidalgo.

Eso no es todo. Funcionarios de varios organismos internacionales y de organizaciones locales que trabajan en temas de migración y de niñez, que fueron entrevistados, coinciden en que los centros de operación de esas redes ilegales en muchas ocasiones son casas aledañas al Miguel Hidalgo. En esos lugares, que aparentemente no tendrían nada de sospechoso, los "jefes" "guardan" a los menores junto con el resto de mercancías — contrabando o drogas - que también intercambian. De tal modo que arrendatarios y vecinos de igual forma se beneficiarían de estas formas de explotación infantil recibiendo ganancias económicas por el costo del arriendo, por su silencio y complicidade incluso, en ciertos casos, otro tipo de "beneficios" como "permisos" para abusar sexualmente de esos menores migrantes.

El modus operandi de esa realidad paralela que se teje en la contracara del Miguel Hidalgo termina favoreciendo, de diversos modos, a mucha gente: familiares de canguritos, migrantes, tratantes, polleros, autoridades locales, transeúntes, tapachultecos dueños de casas céntricas, entre otros; a todos menos a esos menores migrantes. Quizá uno de los problemas más graves que esconden esos personajes urbanos y la "distinción" vinculada a ellos es que si bien se los identifica y se los nombra —animalizándolos-, al igual que a las domésticas, la permanente injusticia en la que viven queda puesta a la sombra. Son niños y adolescentes que a los 6, 10 o 15 años ya han atravesado por experiencias iguales o aún más nefastas que un adulto migrante. Sin duda aquello que viven los canguritos es uno de los aspectos más complejos y tétricos no solo de la contra cara de este espacio central, sino también de la migración indocumentada en tránsito por la frontera sur chiapaneca.

\section{Esos otros migrantes}

Tal y como lo habíamos sugerido previamente, a diferencia de las domésticas y de los canguritos, cuya presencia en el parque central es identificada, la de esos "otros migrantes" indocumentados, como los nombró Amalia, parecería no ser tan distinguible, a pesar de que al igual que los canguritos diariamente rondan el parque central y, como las domésticas, es en ese mismo espacio urbano donde suelen ser contratados 
como mano de obra barata. Quizá esto se deba a que esos otros migrantes no tienen ninguna particularidad visible que los distinga. Es más, la mayoría de ellos son migrantes indocumentados en tránsito cuyo paso por el parque central es sumamente fugaz. Sin embargo, este razonamiento resulta demasiado simple y no aporta mayormente al análisis propuesto. Al tener en cuenta que el parque central habría sido designado como el escenario para la contratación de domésticas, dando paso a la normalización de una serie de prácticas sociales ilegales y cargadas de diversas formas de violencia, se nos iluminan otro tipo de respuestas frente a esos otros migrantes.

La histórica, estratégica y ambivalente "distinción" hacia las domésticas y con ella la asignación del parque como el lugar para su contratación y semanal recreación, de alguna forma habrían marcado al Miguel Hidalgo como el lugar donde habitualmente se tolera la presencia y la gestación de un modo de relacionamiento hacia los indocumentados. No obstante, esa relación entre las domésticas y el parque de cierto modo habría monopolizado lo que ocurre con los migrantes indocumentados, impidiendo visibilizar todo lo otro que también opera en ese espacio urbano. Es decir, que el parque estaría automática y exclusivamente relacionado con esas tradicionales figuras urbanas, donde aquello que se permite y espera que esté presente son esas "otras" familiares junto con una serie de prácticas sociales que se han configurado a su alrededor. Casi como si se hubiera tejido un velo sobre ese espacio urbano que solo deja entrever estratégicamente ciertos aspectos relacionados con la tradicional figura de las domésticas, y últimamente de los canguritos, pero que a la vez oculta a la sombra una realidad paralela. La construcción de ese velo da pie para que se normalicen una diversidad de ilegalismos y violencias, y para que, a la sombra, diariamente operen diversos tipos de ilegalismos. Si automáticamente se asume que el parque es el lugar de las domésticas, todo lo demás quedaría velado.
Diariamente esos otros migrantes hacen una parada estratégica en el Miguel Hidalgo. A pesar de que localmente se los agregue bajo una categoría supuestamente homogénea, la de migrantes indocumentados, entre ellos existen algunas particularidades. Por un lado, hay diferencias etáreas y de género. La gran mayoría son hombres jóvenes entre 19-25 años, aunque también pueden encontrarse en el parque a niños(as) y adolescentes - que todavía no han sido atrapados por las redes de explotación infantil-, así como adultos de edad media indocumentados. Generalmente, llegan hasta este parque más hombres migrantes que mujeres, aunque la presencia femenina - a parte de las domésticas - está incrementando cada vez más. Por otro lado, aun cuando en su gran mayoría se trata de indocumentados provenientes de Centroamérica, no es del todo inusual encontrarse con migrantes oriundos de países sudamericanos, africanos o de otras latitudes, que están en tránsito al norte o que en algunos casos se encuentran a la espera de una respuesta de parte del Estado mexicano a una solicitud de refugio, de protección complementaria o para la obtención de papeles migratorios. Sin importar dichas particularidades, usualmente los migrantes llegan hasta este espacio urbano con el fin de reunir dinero sea para continuar su trayecto o para solventar su estancia temporal o definitiva en la ciudad.

Entre esos otros indocumentados también se ha pasado la voz de que el Miguel Hidalgo es un lugar propicio para encontrar "chambas", ya sea para laborar por un par de días, semanas o inclusive un par de meses. Ser contratado en el mercado informal tapachulteco puede ser decisor dentro de sus proyectos migratorios. De hecho, puede servir como catapulta para continuar la ruta o eventualmente para modificar el proyecto migratorio inicial y optar por asentarse de manera temporal, y en ciertos casos definitiva en Tapachula. $\mathrm{Ni}$ se diga la relevancia que puede tener la parada en el parque cuando esos migrantes son engañados y "atrapados" por redes de tráfico y trata de personas. 
La mayoría de ellos se entera de la existencia de ese mercado informal porque alguien más se lo contó: un familiar o conocido, algún migrante en el medio de la ruta o incluso al albergarse en la casa del migrante albergue Belén o en algún otro paraje o cruce del tramo fronterizo por el que transitan. Una vez en el Miguel Hidalgo esperan que algún empleador tapachulteco les ofrezca trabajo. Unos aguardan en pares, en tríos o en grupos de máximo cuatro personas, sentados en las bancas o en las jardineras o deambulando por el parque. Incluso muchos migrantes mientras esperan aprovechan para reunir un par de pesos pidiendo caridad a los transeúntes.

Para muchos indocumentados el parque también se vuelve el espacio donde pernoctan. Algunos, después de cruzar el río Suchiate, llegan directamente ahí, y otros cuando se les termina su tiempo de estancia en el albergue para migrantes Belén suelen acomodarse entre las bancas y jardineras del parque. Sin embargo, dormir en el Miguel Hidalgo asegura pasar hambre y riesgos bastante grandes como vincularlos a esas redes ilegales como estrategia de subsistencia.

El proceso de contratación de esos otros migrantes es muy similar al que se utiliza con las domésticas. Laúnica diferencia es que no solo se realiza durante la rutina dominical, sino también a lo largo de la semana. En la gran mayoría de las veces esos "otros indocumentados" simplemente acatan órdenes y aceptan cualquier condición laboral. Su necesidad es tan grande, debido al poco dinero que traen o porque en la ruta migratoria fueron asaltados o extorsionados, que cualquier oferta suele ser aceptada. Generalmente se emplean en nichos laborales que antes eran ocupados por chiapanecos que han migrado. Así, suelen ser contratados como albañiles, carpinteros, pintores, plomeros, jardineros, electricistas, mecánicos e incluso puede ser que se contraten jornaleros por día, o mano de obra barata para trabajos pequeños. Para las mujeres, el principal nicho laboral es el de empleadas domésticas, meseras en restaurantes o bares e inclusive como cocineras o costureras. En cualquiera de los casos al tratarse de contrataciones informales, fuera de la ley y sin ningún control, las horas y la intensidad laboral casi siempre superan al mínimo pago que estos otros migrantes reciben. De igual modo, los contratos suelen ser verbales, lo cual impide tramitar alguna forma migratoria, sobre todo si se trata de trabajos semanales o por más tiempo. Tampoco cuentan con seguro o prestaciones sociales, y puede ser que fácilmente caigan en despidos injustificados e intempestivos y que también sean engañados al respecto del trabajo que harán y/o del salario que ganarán. De este modo, toda una serie de violaciones a sus derechos laborales y como migrantes se normaliza en este espacio céntrico, sin el menor control y a la vista de todos. Si a esa práctica rutinaria de contratar a esos otros migrantes de manera informal a la sombra del Miguel Hidalgo, se suma la enorme necesidad que ellos tienen por conseguir dinero, se puede vislumbrar entonces por qué diferentes redes de ilegalismos han hecho del parque central su punto de operaciones.

\section{Punto de enganche}

A la sombra del Miguel Hidalgo también se esconden redes de tráfico y trata de personas. El modus operandi de estas redes es preciso, silencioso y casi no deja evidencias. Los traficantes, o polleros, y los tratantes involucrados en una de las actividades ilícitas, que junto con el narcotráfico y el tráfico de armas resulta ser una de las más lucrativas del mundo, suelen buscar cotidianamente a sus víctimas entre las domésticas, canguritos y los otros migrantes que llegan hasta el parque. Aquellos polleros que sólo buscan "clientes" que les paguen por el cruce hasta Estados Unidos no tienen ninguna preferencia entre los indocumentados. En cambio, los tratantes suelen privilegiar la selección de mujeres y menores migrantes para vincularlos directamente con redes transnacionales de comercio y explotación sexual, venta de infantes e incluso tráfico de órganos. ${ }^{20}$ El éxito del funcionamiento de este "ovillo 
invisible", como lo designa justamente una funcionaria de un organismo internacional entrevistada, reside en el enorme conocimiento que estos nefastos personajes tienen de lo que ocurre en la contra cara de ese parque. ${ }^{21}$ Ellos saben qué trabajos se ofertan, quiénes son los empleadores(as), las horas y los días de la semana designados para hacer las contrataciones, qué se tolera y qué no, y sobre todo la enorme necesidad que tienen esos indocumentados por encontrar un nicho laboral y/o el gran anhelo por continuar con la ruta hasta el norte. Es decir, se valen de la dinámica misma del mercado informal que se ha montado en este espacio central para engañar y enganchar a sus víctimas. Ocultándose bajo discursos de falsos empleadores(as) y casi siempre poniendo en marcha el mismo proceso de contratación y de relacionamiento hacia los indocumentados, se vuelven prácticamente irreconocibles logrando atrapar a sus víctimas, convirtiéndolas en mercancías intercambiables.

El enganche de las víctimas solo es posible a través del engaño. Las enormes expectativas e inmensa necesidad de encontrar un trabajo, que lleva a esas migrantes hasta el parque central, son las bases para configurar una precisa mentira que rápidamente las atrapa. Casos como emplearse de domésticas, de "tableras" en los centros botaneros, de meseras o vincularse al mundo del modelaje son muy comunes. Ese engaño solo se sostiene porque está acompañado de diversas amenazas que son fabricadas a partir de la particular situación de las migrantes: denunciarlas por ser indocumentadas y supuestas ladronas; chantajearlas con "reportar" a sus familias en el país de origen sobre sus actos usando evidencias que las muestran degradadas en el comercio sexual; intimidarlas con no pagarlas, con la vigilancia y la permanente violencia verbal, física y sexual, e incluso con su propia muerte. Esas amenazas subsisten porque se fundan en una relación de dominio donde el tratante, por un lado, acapara toda la información de lo que en realidad sucederá con su víctima y, por otro, acentúa las enormes desventajas sociales de los indocumentados, la discriminación, la invisibilidad, su enorme vulnerabilidad y su miedo. Esas inconcebibles experiencias de esclavitud contemporánea dejan marcas imborrables en los cuerpos de todas las otras mujeres y niños(as) que son atrapados. Son huellas que difícilmente se irán y que están presentes porque parecería "normal" que los sin papeles habiten esos márgenes cargados de violencia.

Vale la pena recalcar que las redes de polleros también usan el parque como punto de enganche, y su modus operandi es muy similar al de las redes de trata que hemos descrito. Su forma de enganche es ofertando sus servicios para cruzar desde la frontera sur a los migrantes hasta Estados Unidos. El precio dependerá del pollero, pero no desciende de 1.000 dólares. Algo que ha venido ocurriendo en los últimos años es que debido al lucrativo negocio que es la trata de personas a escala mundial, los polleros cada vez más están vinculados con redes de trata y narcotráfico. Así, si bien se presentan como polleros, engañando a los migrantes al respecto del servicio que supuestamente dan y casi siempre cobrándoles una primera cuota; a mitad del camino suelen secuestrar a los indocumentados insertándolos en el mercado de la trata de personas o, últimamente, en el nefasto mundo del secuestro propiciado por cárteles de narcotráfico que operan localmente como Los Zetas.

Por otra parte, hay que insistir que existe una industria montada en la que no solo tratantes están involucrados sino, y al igual que en las redes de explotación laboral que atrapan a los canguritos, muchísima más gente. Entre ellos: dueños de bares, hoteles y restaurantes; policías y agentes migratorios; autoridades locales, polleros y tratantes, si hablamos de personajes locales. Todos coordinados y beneficiándose de diversas maneras a costa de la deshumanización de los migrantes. Es más, este infausto sistema de mercantilización y extrema violencia hacia los indocumentados opera casi siempre vinculado a redes transnacionales que han trazado rutas globales ocultas 
para el tráfico y trata de personas. Dentro de éstas, México y específicamente la frontera sur chiapaneca es solamente una parada más. Así, a la sombra global los indocumentados parecen convertirse en simples mercancías intercambiables y desechables que van de la mano de tratantes y traficantes por las autopistas clandestinas de esa realidad inaudita producto de la globalización contemporánea. Que el Miguel Hidalgo sea un mercado para lo informal o un punto de enganche para la trata y el tráfico de personas también se debe a que han delimitado fronteras sociales invisibles, marginando ese espacio como el lugar de los "otros", los indocumentados. Al parecer un lugar donde en silencio todo puede suceder.

\section{¿Hasta dónde?}

El Miguel Hidalgo, que alguna vez fue destinado como lugar de encuentro para los tapachultecos, es hoy un espacio lleno de fronteras sociales, en donde a la sombra, inenarrables experiencias de violencia normalizada hacia esos "otros", los históricamente marginados, los migrantes, ocurren todos los días y a la vista de todos. Sin duda, la localización espacial del análisis aporta un elemento sustantivo a la hora de comprender cómo y por qué opera la violencia normalizada hacia los migrantes indocumentados. Esta propuesta analítica efectivamente nos ilumina para comprender en que si bien esa geografía de la desigualdad determina los procesos sociales y las diversas formas de violencia que estos producen, tienen singularidades. Es decir, que a pesar de que la violencia estructural es producto del modo de organización de los Estados capitalistas, esta no puede generalizarse o menos aún ser comprendida de manera uniforme; la violencia estructural, política y simbólica, dimensiones diversas de la violencia normalizada, se ejercen en espacios cotidianos determinados, operan de modos específicos y se traducen en prácticas locales con rasgos particulares. Esas diversas formas de violencia normalizada que se tejen a la sombra del Miguel Hidalgo deben entonces ser indagadas desde su especificidad, como producto de un contexto local particular, en este caso el Estado mexicano, la frontera sur chiapaneca y Tapachula, sin dejar de hacer una continua referencia al contexto global el cual también las determina.

De hecho, esas formas de violencia normalizada que operan a la sombra del Miguel Hidalgo se reproducen y se extienden por Tapachula. Sólo por nombrar algunos ejemplos adicionales, que forman parte de la dinámica diaria de esta ciudad: las esquinas de las calles principales donde están otros menores migrantes, los "limpiaparabrisas" o los payasitos de los semáforos; el basurero municipal de Tapachula donde los "basureritos", indocumentados guatemaltecos, se disputan con los gallinazos la basura de la ciudad; Las Huacas, zona de tolerancia donde indocumentadas sobre todo de Centroamérica — adultas y menores de edad - trabajan en el comercio sexual. Además, otros espacios a la sombra - cruces y parajes por donde transitan o paran los indocumentados - cada vez se multiplican más a lo largo de la frontera sur chiapaneca: las vías férreas, el Tren de la Muerte, La Arrocera en Huixtla, rutas de extravío, casas de seguridad para secuestros a indocumentados, entre otros. Sólo localizando espacialmente nuestro análisis podemos efectivamente comprender que esas nefastas experiencias de las que son víctimas las domésticas, canguritos y los otros migrantes alarmantemente son parte del modus operandi de la sociedad tapachulteca y del Estado mexicano.

Esas fronteras sociales que terminan construyendo espacios física y/o socialmente marginados, como el parque, deben además comprenderse como resultado de la percepción que los usos tienen de los "otros". En 2008, el Instituto para la Seguridad y la Democracia, AC-Insyde, y Parametría, llevaron a cabo una encuesta en 600 hogares en Tapachula con el objetivo de medir la percepción que los tapachultecos tienen sobre la migración. Entre los interesantísimos resultados que 
arroja esta encuesta están que 74\% de los encuestados percibe como grave o muy grave la llegada de migrantes a Tapachula y $60 \%$ cree que la migración no trae ningún beneficio. Por su parte, $62 \%$ de los tapachultecos(as) encuestados(as) dijeron no tener ningún tipo de relación con los migrantes. 43\% afirmó que no les gusta asistir a lugares frecuentados por migrantes - por ejemplo el parque Miguel Hidalgoy $40 \%$ piensa que al ver un migrante en la calle este lo va a asaltar. El 65\% cree que Tapachula es una ciudad peligrosa o insegura, y $73 \%$ cree que se debe a vivir cerca de la frontera con Centroamérica (Insyde y Parametría, 2008). Algunos datos evidencian cómo las fronteras sociales erigidas hacia los migrantes indocumentados no solo son parte del Miguel Hidalgo, sino también de la rutina diaria de esta ciudad fronteriza. Sólo así se comprende entonces cómo y por qué parecería que existe un "normal" modo de relacionamiento con las domésticas, los canguritos y esos otros migrantes, donde se los silencia, niega, explota y violenta continuamente. La tolerancia estratégica en esta ciudad al parecer impide ver las evidentes formas de violencia rutinaria que se tejen alrededor de esos personajes urbanos. Una violencia tan cotidiana y evidente que ya ni se la ve.

Esa localización espacial irremediablemente nos lleva a una pregunta mayor, que se vincula con el generalizado contexto de violencia impune que ha cubierto el territorio mexicano: ¿hasta dónde nos llevará esa tolerancia estratégica frente a todo lo que sucede a la sombra? ¿Hasta dónde y hasta cuándo seguiremos ocultando todo aquello que está a la vista de todos? Cuando perdemos la capacidad de distinguir las formas de violencia, cuando ocultamos la guerra que muchos sufren bajo un supuesto "tiempo de paz", perdemos la capacidad de exigir el cumplimiento de derechos y el respeto a la dignidad humana. Cuando ya no distinguimos las violencias y las ocultamos a la sombra, nos vamos acercando a la inhumanidad. ¿Hasta dónde seguimos?

\section{Notas}

${ }^{1}$ Este artículo forma parte de la investigación "Frontera sur chiapaneca: el muro humano de la violencia", elaborada en el marco del programa de maestría en antropología social de la Universidad Iberoamericana de México, con la beca del Consejo Nacional de Ciencia y Tecnología, Conacyt, otorgada durante el período 2007-2009

${ }^{2}$ Philippe Bourgois (2004) distingue entre la dimensión estructural, política, simbólica y cotidiana de la violencia. Si bien esta diferenciación es un apoyo analítico, esas dimensiones no han de considerarse autoexcluyentes; todo lo contrario, estas coexisten, dependen y se alimentan mutuamente. Están directamente interrelacionadas con el funcionamiento y la regulación de los Estados capitalistas y suelen expresarse indistintamente como parte de un "orden normal" en la rutina cotidiana de aquellos espacios social y/o físicamente marginados (Bourgois, 2004: 426). El aporte de este antropólogo se suma al de varios otros que desde finales de la década de 1990, a partir de arriesgadas investigaciones etnográficas en espacios urbanos y rurales marcados por el conflicto y la guerra, han hecho importantes aportes en la forma de analizar la multidimensionalidad y normalización de la violencia en la vida cotidiana de espacios social y físicamente marginados. Entre otros aportes están los de: Carole Nagengast (1994), Philippe Bourgois (2001, 2004), Nancy Scherper-Hughes (1992, 1994, 1996 2004), Carolyn Nordstrom (2004, 2007), Veena Das y Deborah Poole (2004), Veena Das (2007), Linda Green (2004), Paul Farmer (2005), entre otros.

3 El mayor riesgo de "naturalizar a la violencia" o normalizarla es que esta deja de ser un problema y su uso ordinario se legitima y justifica, implicando un enorme peligro: únicamente actos extraordinarios de violencia llamen la atención y se conviertan en un problema público a ser resuelto, pasándose por alto la violencia ordinaria, aquella estructural, política y simbólica, y los 
profundos y dramáticos efectos diarios que producen (Bourdieu, 2004, Tomasini, 2002). Algo que parece ser parte de la vida cotidiana no solo del Miguel Hidalgo o de Tapachula, sino también de la frontera sur chiapaneca.

4 Entre los informantes entrevistados durante el período mayo-julio de 2008 y marzo-abril de 2009, constan: cónsules, funcionarios públicos, miembros de organismos internacionales, de organizaciones locales de la sociedad civil, de los albergues para migrantes, periodistas, así como algunos tapachultecos y más de una treintena de migrantes indocumentados en tránsito en diverso espacios fronterizos — cruces y parajes.

${ }^{5}$ A partir de 2005 los migrantes en tránsito deben cubrir los $300 \mathrm{~km}$ que separan a Tapachula de Arriaga, ciudad desde la que actualmente parte el tren, y lo hacen de diversas maneras: a pie, en combi, en camiones de doble fondo, y en muy raras ocasiones en taxis o automóviles particulares. Este forzoso traslado hasta Arriaga ha implicado un incremento en las formas de violencia hacia los indocumentados. Entre ellas están: sortear siete garitas migratorias; cruzar caminos inhóspitos exponiéndose a animales y climas extremos; a extorsiones, asaltos, secuestros, violaciones y asesinatos cometidos por bandas de delincuentes organizados o por autoridades locales. Además de las nefastas formas de violencia que acompañan al viaje en el tren de carga.

${ }^{6}$ Agente migratorio de INM en Tapachula. Entrevista personal, mayo de 2008.

7 El antropólogo Arun Kumar Acharya (2009), investigador de la trata de mujeres en Tapachula y en México, afirma que la mayor dificultad metodológica que existe a la hora de trabajar con mujeres traficadas, es que ellas son parte de una "población oculta". Este antropólogo sugiere adoptar varios métodos que se adapten a esa compleja realidad a estudiar. Uno de ellos es el método de "bola de nieve", snowball sampling method (Watters and Biernacki, 1989; Acharya, 2009: 162). La sugerencia metodológica propuesta por Acharya es un aporte acogido como método de análisis para este estudio. Además, hemos privilegiado la observación in situ de la dinámica dominical del parque central, estancias diarias, de una a dos horas, a lo largo del período de trabajo de campo, realizando entrevistas a informantes clave, así como a transeúntes, comerciantes y pobladores locales que cotidianamente llegan y habitan el parque.

${ }^{8}$ Pierre Bourdieu (1988) concibe los espacios sociales como sistemas de posiciones sociales. Cada posición social estaría definida por relaciones de poder. Entre una posición social y otra se configuran distancias o diferencias sociales separando posiciones inferiores o superiores. Desde la perspectiva de este autor, las diferencias sociales también son concebidas como "distinciones". Así, el espacio social sería, en definitiva, un sistema de diferencias sociales o "distinciones". En un sistema jerárquico y desigual, si bien las "distinciones" aparecerían como parte de un "orden natural", son producidas por relaciones de poder que expresan diferencias económicas y culturales. Las distinciones, sugiere Bourdieu (1988), al producirse en la vida cotidiana se confirman, se reproducen y renuevan continuamente pero siempre fundadas en diferencias de poder. Este concepto es una guía para comprender las interrelaciones que se tejen hacia los indocumentados en el parque central.

9 Ver: Arriola (1995), De León Orozco (1996), Centro de Derechos Humanos Fray Matías de Córdova, A. C. y El Colegio de la Frontera Sur, Ecosur, (2004), Casillo, Toussaint Ribot y Vásquez Olivera (2006), Rojas Weisner, Fernández Casanueva y Ángeles (2008). Además se realizaron las siguientes entrevistas: Vicecónsul de Guatemala en Tapachula (junio 2008 y abril 2009), director de la Jurisdicción Sanitaria (abril 2009), directora del Centro de Derechos Humanos Fray Matías Córdova, A. C. (junio 2008 y mayo 2009), Florencio, Jacinta y Mariano, jornaleros guatemaltecos (julio 2008).

${ }^{10}$ Aura Marina Arriola (1995), en su estudio Tapachula "la perla del Soconusco". Ciudad estratégica para la redefinición 
de las fronteras, se remite a un documento del Archivo Municipal de Tapachula fechado el 16 abril 1914, donde se hace referencia a un conflicto entre una indígena guatemalteca de 30 años, de oficio lavandera, y su patrono. Este dato lo usa para ejemplificar cómo la "tradición de las sirvientas" en Tapachula es de larga data (Arriola, 1995: 117).

${ }^{11}$ Entre los procesos más relevantes se incluyen: los efectos directos de los conflictos armados en Centroamérica durante la década de 1980; la recepción de refugiados sobre todo guatemaltecos; el incremento de la pobreza y el decrecimiento de las condiciones de vida; efectos de huracanes Mitch en 1998 y Stan en 2005 y la presencia de las maras y la violencia que generan (Kauffer, 2000; Castillo, 2001, 2003, Casillas, 2006).

${ }^{12}$ La socióloga Carmen Fernández Casanueva analiza las redes sociales en el proceso de migración, por ejemplo de trabajadoras domésticas y el rol de las familia para promover y gestar procesos migratorios. Ver: "Building Migratory Trajectories: Guatemalans, Salvadorians and Hondurans at the Southern Mexican Border", tesis de doctorado en Sociología, University of Essex, 2006.

${ }^{13}$ A pesar de que no se sabe con certeza cuántas domésticas trabajan en Tapachula ni de dónde provienen, se conjetura que $90 \%$ proviene de la franja fronteriza occidental de Guatemala (Sin Fronteras, 2005: 11).

${ }^{14}$ En 2004 el CDHFM junto con El Colegio de la Frontera Sur, Ecosur, llevaron a cabo un estudio cuantitativo y cualitativo, con 94 trabajadoras domésticas en Tapachula, con el objetivo de analizar sus condiciones laborales y el cumplimiento de sus derechos. Entre los hallazgos de la investigación consta que $73 \%$ de las migrantes laboraba más de 8 horas, 25\% dijo tener demasiada carga laboral y poco sueldo, 19\% afirmó haber recibido algún tipo de maltrato o abuso (CDHFM y ECOSUR, 2004).

${ }^{15} \mathrm{La}$ peculiar manera que estos migrantes menores de edad tienen de cargar las mercancías que venden, es lo que ha dado origen a su sobrenombre. Las paletas, caramelos, chicles, cigarrillos, chocolates, fósforos, encendedores, son colocados en una caja de madera que cuenta a cada lado con una especie de cinturón de cuero, de hilo tejido o de tela. Esos cinturones se amarran al cuello de esos niños y adolescentes de tal manera que la caja de madera cuelga hasta sus caderas semejando a un canguro. La gran mayoría de estos menores migrantes venden esos productos, salvo por los "burros" quienes además venden diferentes tipos de drogas.

${ }^{16}$ Rodolfo Casillas (2006) en su estudio La trata de mujeres, adolescentes, niñas y niños en México. Un estudio exploratorio en Tapachula, Chiapas, a partir de un extenso estudio sobre trata de mujeres, adolescentes, niños y niñas en Tapachula, detecta que la edad de los canguritos puede variar entre 6 y 17 años. La mayoría se encontraría entre 14 y 17 años, en menor proporción de 10-13 años y una minoría entre 6-9 años. La mayoría no ha terminado la primaria. Algunos no terminaron la secundaria y sólo una pequeña parte nunca asistió a la escuela (2006: 95). ${ }^{17}$ Ver: Sin fronteras (2005), Casillas (2006), GREDMIG (2006), ACNUR (2007), Caballeros (2007), Instituto de Desarrollo Humano de Tapachula et al, (2007), Escobar Sarti (2008).

18 A diferencia de las trabajadoras domésticas, la presencia de los canguritos en el parque central no es de larga data. Esta ha venido incrementándose en la frontera sur chiapaneca. Tanto el historial migratorio centroamericano, la cercanía geográfica, la agudización de la pobreza a lo largo de las dos últimas décadas, como los efectos provocados por los huracanes Mitch, en 1998, y Stan en 2005, serían algunas causales que explicarían en parte la llegada de menores migrantes indocumentados y que darían pistas para comprender específicamente la presencia de los "canguritos" en Tapachula. No obstante, existen dos factores adicionales que estando vinculados con esas causales previamente enunciadas, son determinantes directos para la migración de esos menores: l- la necesidad de reunificación familiar inclusive si es de manera clandestina de la mano de polleros, 2- el incremento de la violencia en los países de origen. Así, cuando a 
un contexto de pobreza, de falta de oportunidades, de reconfiguración familiar e incluso de total abandono familiar, se suma la violencia cotidiana provocada por las maras MS 13 o Barrio 18 y el enfrentamiento de éstas con las policías locales; se puede intuir por qué migrar solo cuando se tiene 6, 10 o 15 años es una salida (Sin Fronteras, 2005; Casillas, 2006; GREDEMIG, 2006; ACNUR, 2007; Escobar Sarti, 2008; ACNUR, 20007; Instituto de Desarrollo Humano de Tapachula et al., 2007).

19 En septiembre de 2009, la CNDH Tapachula emitió una recomendación al Ayuntamiento de Tapachula en la que pide se respete la integridad física de los menores que trabajaban en la ciudad. Esta institución, después de una investigación hecha en la ciudad, afirmó que las condiciones en las que se encontraban esos menores migrantes es "deplorable porque no sólo son víctimas de explotación laboral sino también sexual” y la responsabilidad es por omisión tanto del Ayuntamiento como del INM que no atendieron en su momento el problema que se dio a conocer en los medios donde se mostraban las condiciones de riesgo en la que laboraban los menores de edad. La CNDH recomendó a ambas instituciones que asuman la parte que les corresponde. Esta institución ha recibido denuncias de personeros del Ayuntamiento que llegan en ocasiones a pedirles dinero a cambio de dejarlos trabajar sin que los molesten (Naveda E. y Palma C., 2006; Zúñiga, Rubén, 2006; Expreso de Chiapas, 2009).

20 Según la Organización Internacional del Trabajo, el tráfico y la trata de personas produce ganancias anuales por más de 9,500,000,000 de dólares a escala mundial. Esta misma organización afirma que entre 2005 y 2007 más de 2,450,000 personas fueron reclutadas con fines de explotación laboral o económica. De ellas $56 \%$ fueron mujeres y niñas. En el caso de las víctimas de explotación sexual, 98\% fueron mujeres y niñas. En México, según datos de Inegi, 16,000 menores de edad son sujetos de explotación sexual cada año y 85,000 son vinculados con pornografía clandestina. Se sabe que en
21 de las 32 entidades estatales existen redes de turismo sexual (OIM, 2006; Méndez, 2007). La OIM, por otra parte, afirma que México es uno de los principales países de origen de víctimas de trata de personas que son llevadas hasta Estados Unidos para su explotación. Asimismo según el informe presentado en 2008 por la Fiscalía Especializada en Violencia contra las Mujeres y la Trata de Personas, se identificaron a las siguientes entidades estatales como puntos de trata: Coahuila, Chiapas, Chihuahua, Distrito Federal, Estado de México, Guanajuato, Guerrero, Hidalgo, Jalisco, Morelos, Nayarit, Oaxaca, Puebla, Tlaxcala, Veracruz y Yucatán (CNDH y CEIDAS, 2009).

${ }^{21}$ Entrevista a Asistente de campo y protección del Alto Comisionado de Naciones Unidas para ayuda al Refugiado, ACNUR. Tapachula, mayo, 2009.

\section{Bibliografía}

Ángeles Cruz, Hugo y Martha Luz Rojas Weisner (2000), "Migración internacional femenina en la frontera sur de México", en Papeles de Población, núm. 23, eneromarzo, pp. $127-147$.

Acharya, Arun Kumar (2009), Entrevista en Campos Garza, Luciano. "México el Bangkok de Latinomaerica”, en Revista Proceso en línea, julio 25 2009, Versión digital: http://www.enlineadirecta. info/nota.php?art_ID=100984\&titulo=LUCIANO_ CAMPOS_GARZA_México,_el__Bangkok__de_ Latinoam_rica.html última revisión: 20 de agosto 2009.

Arriola, Aura Marina (1995), Tapachula "la perla del Soconusco". Ciudad estratégica para la redefinición de las Fronteras, Guatemala: Facultad Latinoamericana de Ciencias Sociales.

Ayuntamiento Municipal de Tapachula (2008), Monografía de Tapachula. Versión digital: http://www. municipio.gob.mx/work/templates/enciclo/chiapas/ municipios/07089a.htm. [última revisión: 4 de octubre 2009]. 
Alto Comisionado de Naciones Unidades para el Refugio (2007), Estudio y recomendaciones del ACNUR: Protección de los niños en la frontera sur de México. Niños separados y no acompañados en el flujo migratorio mixto, México: ACNUR.

Bartra, Armando (1995), "Origen y claves del sistema finquero del Soconusco”, en Revista Chiapas, núm. l. México, versión digital: http://www.revistachiapas. org/Nol/chl.html. [última revisión: 1 de noviembre de 2009].

Bourdieu, Pierre (1988), La distinción, Madrid: Taurus.

Bourdieu, Pierre (1999 [1993]), "Efectos de lugar", La miseria del mundo, Buenos Aires: Fondo de Cultura Económica.

Bourdieu, Pierre (2004), "Gender and Symbolic Violence", en Scheper-Hughes, Nancy y Philippe Bourgouis, Violence in war and peace, Londres: Blackwell Publishing, pp. 340-342.

Bourgois, Philippe (2004), "The Continuum of Violence un War and Peace: Post-ColdWar Lessons from El Salvador", en Scheper-Hughes, Nancy y Philippe Bourgouis, Violence in war and peace, Londres: Blackwell Publishing, pp. 425 - 433.

Caballeros, Álvaro (2007), "La compleja relación entre la migración internacional y la niñez", en Mesa Nacional para las migraciones en Guatemala "VozItinerante" MENAMIG, Boletín electrónico, Año 6, núm. 55, versión digital: http://www.menamig.org/boletin/ boletin55.pdf. [última revisión 4 de noviembre de 2009].

Castillo, Manuel Ángel (2001), "Los flujos migratorios en la frontera sur de México”, en Amérique Latine Histoire et Mémoire, Les Cahiers ALHIM, 2/2001, Puesto en línea el 16 junio 2006. Versión digital: http://alhim.revues. org/index603.html. 16 juin 2006, [última revisión noviembre 2009].

Castillo, Manuel Ángel (2003), "Los desafíos de la emigración centroamericana en el Siglo XXI", en Amérique Latine Histoire et Mémoire. Les Cahiers ALHIM, 7/2003, Versión digital: http://alhim.revues.org/ index369.html 14 février 2005, [última revisión: noviembre 2009].

Castillo, Manuel Ángel, Mónica Toussaint y Mario Vázquez Olivera (2006), Espacios diversos, historia en común. México, Guatemala y Belice: la construcción de una frontera, México: Secretaría de Relaciones Exteriores.

Casillas, Rodolfo y Manuel Ángel Castillo (1994), Los flujos migratorios internacionales en la frontera sur de México, México: Secretaría del Trabajo y Previsión SocialConsejo Nacional de Población.

Casillas, Rodolfo (2006), La trata de mujeres, adolescentes, niñas y niños en México. Un estudio exploratorio en Tapachula, Chiapas, México: Comisión Interamericana de Mujeres, OEA, OIM, INM, Instituto Nacional de las mujeres.

Castles, Stephen, Mark J. Millar (2004), La era de la migración, México: Editorial Miguel Ángel Porrúa, Universidad Autónoma de Zacatecas, Secretaría de Gobernación.

Centro de Derechos Humanos Fray Matías de Córdova A.C. y El Colegio de la Frontera Sur (2004), Trabajo y migración femenina en la frontera sur de México, Tapachula: Centro de Derechos Humanos Fray Matías de Córdova A.C. y El Colegio de la Frontera Sur (ECOSUR).

Comisión Nacional de Derechos Humanos (2009), Informe especial de la CNDH sobre casos de secuestros en contra de migrantes, México: CNDH.

Comisión Nacional de Derechos Humanos México y Centro de Estudios e Investigación en Desarrollo y Asistencia Social A.C. (2009), Diagnóstico de las condicionesdevulnerabilidad que propician la tratadepersonas en México, México: CNDH y CEIDAS. Versión digital: http://www.ceidas.org/documentos/Centro_Doc/ Diagnostico_Trata_de_Personas_CEIDAS-CNDH. pdf. [última revisión: 20 de octubre 2009].

Das, Veena y Deborah Poole (ed.) (2004), Anthropology in the Margins of the State, Santa Fe: School of American Research Press. 
De León Orozco, Javier (1996), "Tapachula: ayer y hoy", en Tapachula, la perla del Soconusco, Tuxtla: Universidad de Ciencias y Artes del Estado de Chiapas y Gobierno del Estado de Chiapas.

Due Process of Law (DPLF), Centro de Derechos Humanos Fray Matías de Córdova y Hogar de la Misericordia (2008), La crisis de derechos humanos en la frontera sur de México, México: Due Process of Law.

Escobar Sarti, Carolina (2008), Los pequeños pasos en un camino minado: migración, niñez y juventud en Centroamérica y el sur de México, Guatemala: Consejería de Proyectos.

Expreso Chiapas (2009), "Para proteger a niños migrantes". Expreso Chiapas http://www. expresochiapas.com/noticias/estatal/7797-paraproteger-a-ninos-migrantes.html, viernes 18 de septiembre 2009

Farmer, Paul (2005), Pathologies of Power. Health, Human Rights, and the New War on the Poor, Berkeley: University of California Press.

Fernández Casanueva, Carmen (2006), Building Migratory Trajectories: Guatemalans, Salvadorians and Hondurans at the Southern Mexican Border, Tesis de Doctorado en Sociología, University of Essex.

Galtung, Johan (1975), "Peace: Research, Education, Action", en Essays in Peace Research, vol. 1, Copenhagen: Christian Ejlers.

Gredemig (2006), Niñez y adolescencia migrante en Centroamérica. Análisis sobre las prácticas implementadas en la intercepción, detención, recepción y entrega de niños, niñas y adolescentes a familiares en sus países de origen tomando como marco la Convención sobre Derechos del Niño, GREDEMIG.

Harvey, David (2007 [1977]), Urbanismo y desigualdad social, Madrid: Siglo XXI Editores.

Harvey, David (2003), Social justice and the city, Georgia: The University of Georgia Press.

Harvey, David (2004 [1990]), La condición de la posmodernidad, Buenos Aires: Amorrortu Ediciones.

Harvey, David (2000), Spaces of hope, Berkeley: University of California Press.
Instituto Nacional de Migración (2009), "Forma migratoria de trabajador fronterizo, FMTF", Temas de interés: formas migratorias, versión digital: http:// www.inm.gob.mx/index.php?page/triptico_FMTF. [última revisión: 3 de noviembre 2009].

Instituto Nacional de Migración (2009), "Estadísticas", versión digital: http:/www.inm.gob.mx/index. php?page/Estadistcas_Migratorias. [última revisión: 19 de mayo 2009].

Instituto Nacional de Migración (2007), "Estadísticas", versión digital: http:/www.inm.gob.mx/index. php?page/Estadistcas_Migratorias. [última revisión: 19 de mayo 2009].

International Organization for Migration (OIM siglas en español) e Instituto Nacional de Migración (2006), La trata de personas. Aspectos básicos, México: OIM-INM. Instituto para la Seguridad y la Democracia AC-Insyde y Parametría (2008), Percepciones sobre migración en la frontera sur. Encuesta de vivienda, México: Insyde y Parametría.

Instituto de Desarrollo Humano y Camasc (2007), Niñas, niños y adolescentes en situación de y en la calle. Informe exploratorio y propuesta. Tapachula.

KaufferMichel,Edith(2000), "Refugiados Guatemaltecos en México: del refugio a la repatriación del retorno a la integración", en Boletín CONAPO, año 4, num. 12, México.

Nagengast, Carole (1994), "Violence, Terror, and the Crisis of the State Author", en Annual Review of Anthropology, vol. 23, Annual Reviews, pp. 109-136.

Nordstrom, Carolyn (2004), Shadows of War. Violence, Power, and International Profiteering in the Twenty-First Century, Berkeley: University of California Press.

Nordstrom, Carolyn (2007), Global Outlaws: Crime Money, and Power in the Contemporary World, Berkeley: University of California Press.

Méndez, Alfredo (2007), "La trata de personas, entre los delitos más rentables, documentan los expertos", en Diario La Jornada, 8 de junio 2007, México: Versión digital: http://www.jornada.unam.mx/2007/06/08/ 
index.php? section=politica $\&$ article=016nlpol. [última revisión: 28 de octubre 2009].

Mummert, Gail (1999), "Fronteras fragmentadas: indentidades múltiples”, en Gail Mummer (ed.), Fronteras Fragmentadas, Zamora, Michoacán: El Colegio de Michoacán, Centro de Investigación y Desarrollo del Estado de Michoacán, pp, 11-15.

Naveda. E y Palma.C. Domingo 29 de octubre 2006. "Tapachula: en el falso paraíso", en El periódico de Guatemala.http://www.elperiodico.com.gt/es/20061029/ actualidad/33417/. [20 de octubre 2009].

Rojas Wiesner, Martha Luz (2007), "Mujeres y migración en la frontera sur de México", en Amérique Latine Histoire et Mémoire. Les Cahiers ALHIM, 14 / 2007. Versión digital: http://alhim.revues.org/index2252. html. 9 de octubre 2009. [última revisión: noviembre 2009].

Rojas Weisner, Martha, Carmen Fernández Casanueva y Hugo Ángeles Cruz (2008), "Trabajo y migración femenina en la frontera sur de México", en América Latina migrante: Estado, familia, identidades, Quito: Facultad Latinoamericana de Ciencias Sociales.

Sassen, Saskia (2001), "Spatialities and temporalities of the Global: Elements for a theorization", en Arjun Appadurai, Globalization, Duke: University PressDurhan and London, pp. 260-278.

Scheper-Hughes, Nancy y Philippe Bourgouis (2004), Violence in war and peace, Londres: Blackwell Publishing.

Scheper-Hughes, Nancy y Philippe Bourgouis (1997), "Peace-Time Crimes", en Social Identities, vol. 3, Issue 3, pp: 471-497.

Scheper-Hughes, Nancy y Philippe Bourgouis (1996), "Small Wars and Invisible Genocides", en Social Science and Medicine, XIV International Conference on the Social Sciences and Medicine, vol. 43, Issue 5, pp: 889-900.

Scheper-Hughes, Nancy y Philippe Bourgouis (1992), Death without Weeping: The Violence of Everyday Life in Brazil, Berkeley: University of California Press.
Secretaría de Turismo del Gobierno de Chiapas (2004), Ruta costa Soconusco. Caminos verdes en la tierra del sol, Tuxtla Gutiérrez: Gobierno del Estado de Chiapas.

Sin Fronteras (2005), México y su frontera sur, México: Sin Fronteras I.A.P.

Tomasini, Alejandro (2002), "Violencia, ética, Legalidad y Racionalidad", en Witold, Jacorzynski. Estudios sobre la violencia. Teoría y práctica, México: Editorial Porrúa.

Organización Internacional para las Migraciones. "Mujeres migrantes y trata de personas", Presentación power point. Chetumal: 12 y 13 de octubre 2006, versión digital: http://www.inmujeres.gob.mx/dgpe/ migracion/res/Anexo_30_4.pdf. [28 de octubre 2009].

Villafuerte Solís, Daniel (2008), "Migración y desarrollo en el área del Plan Puebla-Panamá", en Villafuerte Solís, Daniel y María del Carmen García Aguilar (coord.), Migraciones en el sur de México y Centroamérica, México: Editorial Porrúa.

Wacquant, Loïc (2007), Los condenados de la ciudad, Buenos Aires: Siglo XXI Editores.

Watters, John and Patrick Biernacki (1989), "Targeted Sampling: Options for the Study of Hidden Population", en Social Problems, vol. 36, núm. 4, University of California Press, pp. 416-430.

Zúñiga, Rubén (2006) "Para la venta de dulces y cigarros", en Diario Del Sur, Tapachula 〈http://www. oem.com.mx/elsoldetulancingo/notas/n64854.htm, 14 de noviembre 2006>

\section{Entrevistas}

Habitantes fronterizos: Amalia. Tapachulteca y dependiente del almacén ubicado alrededor del parque central. Tapachula, julio 2008).

Migrantes: Florencio. Jornalero guatemalteco. Talismán, julio 2008. Mariano. Jornalero guatemalteco. Talismán, julio 2008. María. Jornalera guatemalteca. Talismán, julio 2008. Luz. Migrante guatemalteca y empleada doméstica. Tapachula, julio, 2008. Andrés 
Valle. Migrante hondureño. Cangurito. Tapachula, abril 2009. Jesús. 14 años. Cangurito. Tapachula, julio, 2008. Braulio. 26 años. Migrante salvadoreño. Parque Miguel Hidalgo. Mayo, 2009. Mery. Migrante hondureña. 18 años. Parque Miguel Hidalgo, Tapachula. Mayo 2008. Raúl.43 anos. Migrante salvadoreño. Parque Miguel Hidalgo. Tapachula. Mayo 2008. Ana. 16 años. Migrante guatemalteca.
Tapachula, junio, 2008. Evelyn. 45 años. Migrante salvadoreña y madre de Wendy. Tapachula, mayo 2009. Carla.17 años. Migrante guatemalteca y doméstica. Tapachula, mayo 2009.

Funcionarios: Asistente de campo y protección del Alto Comisionado de Naciones Unidas para ayuda al Refugiado, ACNUR. Tapachula, mayo, 2009. Agente migratorio del INM .Tapachula, mayo 2008. 